\title{
An Investigation of Transition Experiences of Students with Visual Impairment in Public Universities in Ghana
}

\author{
Sandra Tsoenemawu Sikanku \\ University of Cape Coast, Ghana \\ Email: sandra.sikanku@gmail.com \\ Address: Cape Coast, Ghana
}

\section{Introduction}

Global concern in widening access for persons with disability including the visually impaired was pushed by the tenets stipulated in international conventions such as the Universal Declaration of Human Rights (UDHR) of 1948, the Salamanca Statement of 1994, the United Nations Convention on the Rights of Persons with Disabilities (CRDP), adopted in 2006 and the United Nations Sustainable Development Goals 4 and 10. As a result, inclusive education has been widely accepted as a model for higher education provision (Maher 2009). Inclusion philosophies are experiencing a rapid growth worldwide. There are frameworks that supports the participation of students with disabilities in higher education. For instance, in Europe, this agenda is spearheaded by the European Disability Strategy 2010-2020 (European Commission 2010). This has led to most universities in the European countries to respond by offering structures to improve the learning of students with disabilities (Fernie and Henning 2006). The interventions have led to a surge in the enrolment of students with disabilities including students with visual impairment in universities. For instance, in 2004/5 students with disabilities represented $7.1 \%$ of the total student population in the United Kingdom. By 2013/14, they accounted for 11\% of all full-time undergraduates (Riddell, n.d). Similarly, in Australia, higher education institutions are guided by the Disability Discrimination Act of 1992 to offer specialist disability services to meet their obligations to students with disability, as well as develop course and campus design measures to provide inclusive curriculum and building design to accommodate students with a variety of impairments (Cunninghame, Costello and Trinidad 2016). The proportion of higher education for students with disabilities including students with visual impairment has since increased from 4.4\% in 2007, to 5.8\% in 2014 (Koshy and Seymour 2015). Equally, Ghana, a signatory to all the above mentioned international conventions have domesticated these tenets in its 1992 Constitution, Persons with Disability Act 715, the Education Strategic Plan 20182030, and the Education For All ( EFA) policy. The EFA policy requires all schools, including higher education institutions to adhere to the principle of universal design for learning (Ministry of Education, 2015). This seems to have led to a surge in the number of students with disabilities including those with visual impairment accessing public universities in Ghana. However, despite the upsurge in the enrolment figure, limited research exists on the experiences of students with disabilities enrolled in public universities in Ghana.

\section{Literature review}

Transition to university has become a topic of interest for policy makers and scholars around the world. This is because, student transition to university offers significant challenges to university stakeholders (Briggs, Clarke and Hall 2012). Transitions are part of everyone's life while some can be predictable others are spontaneous. Conceptually, transition may mean different things to different people however, in education, transition is defined as the movement 
of the individual from one position, stage, school or environment to another (Strnadova and Cumming 2014). Transition can be within school or out of school such as moving from secondary to postsecondary including universities. The transition to universities is a crucial process in the lives of young students who earnestly want to pursue higher education. However, many students including those with disabilities approach higher education with mixed feelings. Generally, while transition is perceived as stressful experience for all students, however, it is especially challenging for students with disabilities including those who are visually impaired (Benavente 2015). While most students succeed and thrive at the university, students who are visually impaired encounter numerous difficulties (Hewett, Graeme, and Keil 2014). This is because, disability makes transition a more challenging experience as student with disabilities would have to adapt to their new environment. Georgallis (2015), is of the view that this low level of entry to post-secondary education among this student cohort is not about their ability, but is a result of a dearth of learning opportunity and supports. It appears the difficulties students with disabilities encounter are likely to increases as the students realizes that, the personal support they had in secondary school varies from the one at the university. Evidence shows that, the dropout rate of students with disabilities is almost double as compared with their peers who are non-disabled and that they are less likely to graduate because they are unable to access educational facilities (Bardin and Lewi, 2008; Benavente 2015; Cobb, Simple, Alwell and Johns 2006).

Literature suggests that student with disability transitions in higher education is underpinned by a lack of clarity and agreement as to what is meant by 'transition' and by a lack of theorizing around transition to allow higher education practitioners to move beyond description and evaluation towards explanation and evidence-based intervention (O'Donnell, Kean and Stevens 2016). Though many higher education institutions are in compliance with disability laws, students with disabilities including the visually impaired may still be experiencing ableism in diverse ways through the culture competence of universities. Cultural competence in regard to the ways in which universities seek to respond to meet the needs of students with disabilities including those with visual impairment. Basically, culture competence is an on-going process which is essentially a set of congruent behaviors, attitudes and policies that align in a system of agency or profession to work effectively in cross culture situations (Cross 1989).

Universities have pivotal roles to play in facilitating effective transitions for students including those with disabilities (Ebersold 2011; Mc Guckin, Shevlin, Bell, and Devecchi 2013). This can be achieved through the development of policies to serve as blue prints in providing special education and it related services to students with disability. This is important for the success of students with disabilities in universities. In order to ensure that students with disabilities are not at a substantial disadvantage compared to their non-disabled peers, higher education institutions are required by law to make anticipatory reasonable adjustments for each student with disability through transition plans. However, it is not clearly defined what these reasonable adjustments should be but may include, access to adaptive technology (Hutcheon and Wolbring, 2012; Redpath, Kearney, Nicholl, Mulvenna, Wallace, and Martin 2013) or adjustments in relation to teaching, learning and assessment (Redpath et al. 2013; Riddell and Weedon 2014; Smith 2010). These adjustments should be specific to each individual student need and requirements of the programme (Elcock 2014). Taylor, Baskett, and Wren (2010) are of the view that, the importance of ensuring that these adjustments are in place prior to the student commencing their course of study is very imperative. It is however, uncertain if these provision are adhered to in Ghanaian public universities. It is clear from the literature that most studies on transition on students with visual impairment are well documented from developed countries (Benavente 2015; Hewett, Graeme and Sue 2014). It appears very little is known from low-income developing countries like Ghana. Compared to low incidence disability such as visual impairment, Georgallis (2015), is of the view that students with high incidence disability such as those with learning disabilities are also experiencing an increase in the number of students entering into higher education including universities. Conner (2012) reported the number of students with learning disabilities has tripled in the last 30 years. Despite legislation mandating transition services for students with disabilities, Hawbaker (2003), is of the view that a contradiction exist between rhetoric and action. Students with 
learning disabilities also face daunting challenges in education when leaving high school to enter universities heightening the need for an investigation into the experiences of students with visual impairment in public universities in Ghana.

\section{Theoretical Perspective}

The Self-determination theory which was developed by Deci and Ryan (2000) will be used to unpack the lived experiences of students with disabilities in public universities in Ghana. Self-determination theory proposes that satisfaction of the basic psychological needs for autonomy, competence, and relatedness is necessary for effective internalization and for psychological growth, integrity, and well-being. Wehman (2011) is of the view that "SelfDetermination skills are necessary for transition planning to succeed" This makes this theory suitable for this study.

\section{Research Methodology}

This study will be guided by the philosophical assumption of constructivism which will adopt a qualitative research inquiry that seeks in-depth understanding of social phenomenon within their natural setting. This approach will emphasize words rather than quantification in the collection and analysis of data (Bryman 2012). Qualitative methodology will enable an examination of the actors' experiences through their own narration. The objective of the study is to understand the transition experiences of students with visual impairment about this phenomenon using a case study design.

\section{Research design}

A research design is a type of inquiry within qualitative approaches that provide specific direction for procedures in a research. It is called a strategy of inquiry by other scholars (Denzin and Lincoln 2011). The research design that will be used to study the impact of the delivery of ODL on students with visual impairment in University of Ghana, Kwame Nkrumah University of Science and Technology, University of Cape Coast and the University of Education, Winneba will be a multiple case study. According to Yin (2018), a case study as an empirical method, investigates a contemporary phenomenon (the "case") in depth and within its real-world context, especially when the boundaries between phenomenon and the context may not be clearly evident.

\section{Sampling and Sample technique}

Purposive sampling will be employed to select the universities as well as the participants to be involved in this study. This involves identifying and selecting individuals or groups of individuals that are especially knowledgeable about or experienced with a phenomenon of interest (Creswell, Plano, and Clark 2011). A sample of four Heads of Disability Support Centres, 4 Heads of Student Support Centres, and all Students with visual impairment in the case universities namely: University of Cape Coast, University of Education, Winneba, University of Ghana and Kwame Nkrumah University of Science and Technology will be used for the studies.

\section{Data collection methods}

Data collection is important to enhance the trustworthiness of the findings (Ary, Jacobs, Sorensen and Walker 2014). In this study, dual data collection techniques such as semi-structured interview and document analysis and will be employed in this study. The nature of this study suggests that we recognize the voices of principal agents in the study and in this case, students with visual impairment transition in Ghanaian public universities in the form of interview. Interview is a conversation between two or more parties with the specific goal to obtain information from the respondents (Herman-Kinney, and Verschaeve 2003). The use of semi-structured interview to collect data for this study is consistent with qualitative methodology which seeks to uncover and describe the understanding with key informants share about a situation (Burns, 1996). Through the use of semi-structured interview voices of students with visual impairment in public universities will share their transition experiences. In addition to semi-structured interview, 
data will be collected from documents. Cohen et al (2011) refers to a document as a record of an event or process. In this study, relevant document from the universities such as admission register, disability policy documents, frameworks among others will be analysed.

\section{Entering the Research Site}

According to Ary, Jacobs Sorensen and Walker (2014) ethical consideration is important issue for qualitative researchers in order to gain access to the research site. Therefore prior to conducting the research, permission will be sought from the "gatekeeper" within the university. These are individuals within the organisation who not only support the proposed research but will allow access to particular groups in this case, students with visual impairment. I will seek permission and official consent of the Vice Chancellors of the 4 public universities and Heads of the Resource Centre in Ghana by writing to them. The content of the letter will include the nature of the research, the envisaged timescale for the work and any plans that have been made to anonymise and safeguard the data.

\section{Ethics}

I will officially write to seek ethics approval from the Ethics Committee of my university to warrant the study. All the participants of this study will be written to in order to seek their consent to participate in this study. The nature and purpose of the study, the risk and benefits associated with this study, their right to participate and withdraw at any time, the methods that will be used to collect the data, how confidentiality and anonymity of the data will be guaranteed and how data will be stored and used will be made known to the research participant. Finally, in terms of reciprocation, a written report presenting the findings of the research will be presented to the case universities involved or disseminated at various conference forums.

\section{References}

Ary, Donald, Jacobs, Lucy Cheser, Sorensen, Christine, K. \& Walker, David, A. 2014. Introduction To Research in Education. New York: Wadsworth: Cengage Learning.

Association on Higher Education and Disability. 2015. Supporting Accommodation Requests: Guidance on Documentation Practices. http://ahead.org/resources/documentation-guidance.

Bardin, Julie, A., \& Lewis, Sandra. 2008. "A Survey of Academic Engagement of Students with Visual Impairments in General Education Classes. Journal of Visual Impairment \& Blindness 102 (8): 472-483.

Benavente, Pacheco, Edgar. 2015. Vision Impairment and Transition to University Education. Vision Impairment and Transition to University Education: The role of ICTs. Unpublished $\mathrm{PhD}$ thesis submitted to the Victoria University of Wellington.

Briggs, Ann, R. Clark, Jill, \& Hall, Ian. 2012. "Building Bridges: Understanding Student Transition to University." Quality in Higher Education 18(1): 3-21.

Bryman, Alan. 2012. Social Research Methods. (4 ${ }^{\text {th }}$ ed.). Oxford: Oxford University Press.

Cobb, Brain. Sample, Pat. L., Alwell, Morgen, \& Johns, Nikole. R. 2006. "Cognitive-Behavioral Interventions, Dropout, and Youth with Disabilities: A Systematic Review." Remedial and Special Education 27(5):259-275.

Cohen, Louis., Manion, Lawrence, \& Morrison, Keith. 2011. Research Methods in Education. London: Routlage.

Connor, David. J., 2012. "Helping Students with Disabilities Transition to College." Teaching Exceptional Children 44(5): 16-25.

Cresswell, John, W. \& Plano Clark, Vick. L. 2011. Designing and Conducting Mixed Method Research (2 $2^{\text {nd }}$ ed.). Thousand Oaks, CA: Sage Publication. 
Cunninghame, Ian., Costello, Diane., \& Trinidad, Sue. 2016. Issues and Trends for Students With Disabilities. Perth: Curtin University.

Cross, Terry., Bazron, Barbara. J. Dennis, Kari. W. and Isaacs, Mareasa. R. 1989. Towards A Culturally Competent System of Care, Volume I. Washington, DC: Georgetown University Child Development Center, CASSP Technical Assistance Center.

Deci, Edward. L,.\& Ryan, Richard, M. 2000. "Intrinsic and Extrinsic Motivations: Classic Definitions and New Directions." Contemporary Educational Psychology 25(1): 54-67.

Denzin, Norman. K., \& Lincoln, Yvonna. S. 2011. Handbook of Qualitative Research. Thousand Oaks: Sage.

Hawbaker, Becky. 2003. Students-led IEP Meetings: Planning and Implementation Strategies. Teaching Exceptional Children 3 (5): 22-27.

Ebersold, Serge. 2012. Transitions to Tertiary Education and Work for Youth with Disabilities: Education and Training Policy. Paris: OECD Publishing.

Elcock, Karen. 2014. "Supporting Students with Disabilities: Good Progress, But Must Try Harder." British Journal of Nursing 23(13):758.

European Commission. 2019. European Disability Strategy 2010-2020. Brussels: European Commission.

Fernie, Todd, \& Henning, Marcus. 2006. "From a Disabling World to a New Vision." In Towards Inclusive Learning in Higher Education: developing curricula for disabled students, edited by M. Adams\& S. Brown, 23-31. Oxon: Routledge.

Georgallis, Christine, H. 2015. Transition Programming for Students with Learning Disabilities from High School to College. $\mathrm{PhD}$ thesis dissertation submitted in partial fulfilment of the requirement for the degree of Doctor of Philosophy Special Education Walden University.

Government of Ghana. 2006. Persons with Disability Act, Act 715. Accra: Government of Ghana.

Herman-Kinney, Nancy, \& Verschaeve, Joseph. 2013. "Methods of Symbolic Interactionism." In Handbook of Symbolic Interactionism, edited by L. Reynolds and N. Herman-Kinney, 213-52. Walnut Creek, CA: AltaMira Press.

Hewett, Racheal., Douglas, Graeme., \& Keil, Sue. 2014. "Post-16 Transition Experience of Visually Impaired Young People in England and Wales: Early Findings From a Longitudinal Study." British Journal of Visual Impairment 32(3): 211-222.

Hewett, Racheal, Keil, Sue., \& Douglas, Graeme. 2015. Experiences of Blind and Partially Sighted Young People as They Make the Transition into Higher Education. Visual Impairment Centre for Teaching and Research, University of Birmingham.

Hutcheon, Emily J. \& Wolbring, Gregor. 2015. "Voices of "Disabled" Post-Secondary Students: Examining Higher Education "Disability" Policy Using an Ableism Lens." Journal of Diversity in Higher Education 5(1), 39-49.

Kimball, Ezekiel. W., Wells, Ryan. S., Ostiguy, Benjamin. J., Manly, Cathriene. A., \& Lauterbach, Alexanra. A., 2016. "Students Without Disabilities in Higher Education: A Review of the Literature and An Agenda for Future Eesearch". In Higher Education: Handbook of Theory and Research, 91-156. Springer International Publishing.

Koshy, Paul,\& Seymour, Richard. (2015). Student Equity Performance in Australian Higher Education (2007 - 2014$).$ Perth: National Centre for Student Equity in Higher.

Maher, Marguerite. I. 2009. "Information and Advocacy: Forgotten Components in the Strategies for Achieving Inclusive Education in South Africa?" Africa Education Review 6(1): 19-36.

Mc Guckin, Cornor. Shevlin, Micheal. Bell, Sheena, \& Devecchi, Cristina. 2013. Moving to Further and Higher Education: An Exploration of the Experiences of Students with Special Educational Needs. Dublin: NCSE.

Ministry of Education. 2015. Inclusive Policy. Accra: Ministry of Education.

O'Donnell, Victoria. L., Kean, Marcella, \& Stevens, Gemma. 2017. Students Transition in Higher Education: Concepts, Theories and Practices. The Higher Education Academy. 
Redpath, Jennifer., Kearney, Patricia, Nicholl, Peter., Mulvenna, Maurice., Wallace, Johnathan, \& Martin, Suzanne. 2013. "A Qualitative Study of the Lived Experiences of Disabled Post-Transition Students in Higher Education Institutions in Northern Ireland." Studies in Higher Education 38(9):1334-1350.

Riddell, Sheila. (n.d). The Inclusion of Disabled Students in Higher Education in Europe: Progress and Challenges. Edinburgh: University of Edinburgh.

Riddell, Sheila, \& Weedon, Elisabet. 2014. "Disabled Students in Higher Education: Discourses of Disability and the Negotiation of Identity." International Journal of Educational Research 63: 38-46.

Smith, Maria. 2010. "Lecturers' Attitudes to Inclusive Teaching Practice at a UK University: Will Staff "Resistance" Hinder Implementation?" Tertiary Education and Management 16(3): 211-227.

Strnadova, Iva, \& Cumming, Therese. M. 2014. "The Importance of Quality Transition Processes for Students with Disabilities Across Settings: Learning from the Current Situation in New South Wales." Australian Journal of Education 58(3):318-336.

Taylor, Mark, Baskett, Mike, \& Wren, Cris. 2010. "Managing the Transition to University for Disabled Students." Journal of Education and Training 52(2):165-175.

The Constitution of Ghana. 1992. Accra: Government of Ghana.

UNESCO. (1994). "The Salamanca Statement and Framework for Action on Special Needs." Journal of Visual Impairment 32 (3): 211-222.

Wehman, Paul. 2011. Essentials of Transition Planning. Baltimore, MD: Paul H. Brookes, p.6.

Yin, Robert. K. 2018. Case Study Research and Applications Design and Methods (6 ${ }^{\text {th }}$ ed.). Thousand Oaks, United States: Sage Publication Inc. 